\title{
Genetic Distances for Intra- and Between-Group of Scapharca subcrenata from Yeosu of the Korea
}

\author{
${ }^{\dagger} J$ ong-Man Yoon \\ Dept. of Aquatic Life Medicine, College of Ocean Science and Technology, Kunsan National University, Gunsan 54150, \\ Korea
}

Received: September 1, 2021

Revised: October 28, 2021

Accepted: December 7, 2021

\section{${ }^{\dagger}$ Corresponding author} Jong-Man Yoon

Dept. of Aquatic Life Medicine, College of Ocean Science and Technology, Kunsan National University, Gunsan 54150, Korea. Tel: +82-63-469-1887

E-mail:jmyoon@kunsan.ac.kr

Copyright $\odot 2021$ The Korean Society of Developmental Biology.

This is an Open Access article distributed under the terms of the Creative Commons Attribution Non-Commercial License (http://creativecommons.org/licenses/ by-nc/4.0/) which permits unrestricted non-commercial use, distribution, and reproduction in any medium, provided the original work is properly cited.

ORCID

Jong-Man Yoon

https://orcid.org/0000-0003-2825-681X

Conflict of interests

The authors declare no potential conflict of interest.

Acknowledgements

Not applicable.

Authors' contributions

The article is prepared by single author.

Ethics approval

This article does not require IRB/IACUC approval because there are no human and animal participants.

\section{Abstract}

The oligonucleotides polymers (ON-polymers) were used producing a total of 110 loci unique to each clam population (LUECP) in group one and 132 in group two, respectively, varying in amount of DNA fragments (FRs) from greater than near 50 to a smaller quantity than 1,050 bp. The larger FR amounts (>1,050 bp) are not noticed in the two Scapharca subcrenata groups. The ON-polymer OPD-01 produced 33 LUECP, which were defining each group, almost $300 \mathrm{bp}, 450 \mathrm{bp}$, and $500 \mathrm{bp}$, in the group one. The OPD-15 recognized 22 loci shared by the two clam populations (Loci shared by the two clam populations, LSTCP), a variety of FRs of sizes $300 \mathrm{bp}$ that were equivalent in all specimens. The mean number of LUECP was varied and 1.2-fold greater in the shellfish group two than in the group one. Respecting mean bandsharing (BS) grade outcomes, entities in the shellfish group one $(0.779 \pm 0.011)$ had a little higher BS grades than did entities from the group two $(0.756 \pm 0.009)(p<0.05)$. The entities of the shellfish group one are not tightly gathered with other entities of the group two. The genetic distance (GD) (0.422) of this invertebrate (SUBCRENATA 02 and 01) is 7.41-fold hereditarily distinct to the GD (0.057) of the other invertebrate (SUBCRENATA 22 and 19). The polar dendrogram (PDG) procured by the five ON-polymers underlines two characteristic groups.

Keywords: Clustering, Oligonucleotides polymer (ON-polymer), Polar dendrogram (PDG), Scapharca subcrenata, Shellfish

\section{INTRODUCTION}

This mollusk (Scapharca subcrenata) is one of the most customary crustacean species in winter season of Korea. This invertebrate species is an cost-effectively warm-water shellfish type, being adjacent to the class Bivalvia, order Arocida, family Arcidae, and relatives of the genus Scapharca spread widerange in the Buan bay, Shinan bay, Suncheon bay, Yeoja bay, and several foreshore areas of Korea. This invertebrate is also home-grown to the sand or mud zones covering slime from 5 to $10 \mathrm{~m}$ in deepness. The rough lid guard of this invertebrate kind is blackish mud color, vaulted with gloomy hair, with rose-colored muscle in the internal body. Like other shellfish, the great and granular furrow hollows of this invertebrate are affected deliberately by the marine environments. Most of all, there are distinct alterations in the shell volume, shell color, and muscle pigment of interior feet in keeping with the eco- 
friendly situations of the habitat, for instance prey accessibility, aquatic temperature, and different resident circumstances.

This invertebrate (Scapharca subcrenata) is economically and ecologically very significant bivalves in the Korean peninsula. Even so, these types of invertebrates, those are known chief reproductively (Lee, 1998; Kim et al., 2008), ecologically (Kim et al., 2019), as well as bacteriologically (Shin et al., 2016) are not heritably and/or molecular-biologically studied like other crustaceans. There is a demand to apprehend the innate traits and structure of this invertebrate group with the aim of estimating surely the correctly heritable benefit.

PCR-fundamental examination approaches have been employed to pursuit the inherited characters of several living entities (Zhou et al., 2000; García et al., 2004; Liu et al., 2004; Yoon \& Kim, 2004; Yan et al., 2005; Gelin \& Souty-Grosset, 2006). The genomic markers particular to the lines, the strains, the species, the genera or the geographical groups have been utilized for the perception of entities, linkage, paternity testing, forensic medicine and mutation detection (Koh et al., 1999; Esselman et al., 2000; Kim \& Choi, 2003; Dixon et al., 2004; Araneda et al., 2005; Yamazaki et al., 2005; Godhe et al., 2006; Kim et al., 2006; Yoon \& Kim, 2010; Kang \& Yoon, 2013; Yoon, 2019; Yoon, 2020). The author carried out clustering scrutiny to disclose the Euclidean genetic distances (GDs) of intra- and between-group of Scapharca subcrenata from Yeosu of the Korea.

\section{MATERIALS AND METHODS}

A specimen of 22 invertebrate (Scapharca subcrenata) individuals was obtained from a foreshore of Yeosu city of Korea. DNA analysis should be fulfilled as stated by the separation and extraction methods as before-mentioned by Yoon \& Kim (2004). PCR abstraction was executed on DNA specimens of foot muscle tissues gathered from entities using five oligonucleotides polymers (ONpolymers). The lysis buffer I was mixed to the specimens and this rinsing was repeated several times to clean the specimens. The density of the separated genomic DNA (gDNA) was analyzed grounded on the optical density at $260 \mathrm{~nm}$ by means of a spectrophotometer (Beckman Coulter, Buckinghamshire, UK). The pellets were re-suspended in ultra-pure distilled liquid and then used or frozen at $-79^{\circ} \mathrm{C}$ until needed.

Expansions were fulfilled in a programmable thermal cycler (Perkin Elmer Cetus, Norwalk, CT, USA) by electrophoresis in $1.4 \%$ agarose gels, with PCR marker (Sigma-Aldrich Chemicals, Milwaukee, WI, USA) as DNA molecular weight marker and exposed by staining with ethidium bromide (EtBr) (Oh \& Yoon, 2014). PCR upshots were refined using PCR Purification Kit (Qiagen Korea, Seoul, Korea) monitoring the producer's procedures. The electrophoresed agarose gels were made lighter by ultraviolet (UV) treatment, and the gels were taken a picture operating a photographing apparatus (PECA, Beloit, WI, USA). Five ON-polymers, OPD-01 (5'-ACCGCGAAGG-3'), OPD-02 (5'-GGACCCAACC-3'), OPD-08 (5'-GTGTGCCCCA-3'), OPD-09 (5'-CTCTGGAGAC-3'), and OPD-15 (5'-CATCCGTGCT-3') were shown to make the loci unique to each clam population (LUECP) and Loci shared by the two clam populations (LSTCP) which could be normally estimated.

Similarity matrix (SM) involving bandsharing (BS) grades between unlike entities in the two invertebrate groups was created in company with formula of Yoke-Kqueen \& Radu (2006). Numerical scrutiny products such as Euclidean GDs, means and standard errors (SEs) were assessed by treating the hierarchical clustering platform Systat version 10 (SPSS, Chicago, IL, USA). 


\section{RESULTS AND DISCUSSION}

At this point, the intricacy of the banding shapes fluctuated theatrically amid the ON-polymers from the shellfish di-group, as shown in Fig. 1. Especially, the banding forms were different largely from $550 \mathrm{bp}$ to $850 \mathrm{bp}$ between two clam groups. Particularly, DNA profiles with more fragments were observed in $300 \mathrm{bp}$ than any other molecular sizes in two groups (Fig. 1). Five ON-polymers were used producing a total of 110 LUECP in group one and 132 in group two, respectively, varying in volume of DNA FRs from greater than almost 50 to not more than 1,050 bp, as demonstrated in Table 1. The higher FR amounts (>1,050 bp) are not noticed in the Scapharca subcrenata di-group. The DNA bands acquired by the five ON-polymers ranged from 200 to 1,500 bp in the discus (Symphysodon spp.) (Koh et al., 1999). Sixty-one bands varying from 200 bp to $1,900 \mathrm{bp}$ were explicitly calculated in the ectoparasitic caligid (Lepeophtheirus salmonis) (Dixon et al., 2004). The amounts of the DNA FRs also fluctuated broadly, from 90 to 2,400 bp in Gracilaria vermiculophylla and G. chorda (Kim \& Yoon, 2018). Yoon (2018) also reported that the greater FR sizes (>1,100 bp) are not detected in the razor shellfish (Solen corneus) bi-group.

In this study, the BS grade between entity no. 04 of the group one and no. 09 of the group one was 0.478 , which was the smallest observed, as displayed in Table 1 . The BS grade between individuals' no. 06 and no. 08 was 0.921 that was the utmost grade in the Scapharca subcrenata groups. In the present study, the five ON-polymers OPD-01, OPD-02, OPD-08, OPD-09 and

Table 1. Trigonal SM for pairwise comparison of BS grades of group one and two, separately, of Scapharca subcrenata from Yeosu of Korea

\begin{tabular}{|c|c|c|c|c|c|c|c|c|c|c|c|c|c|c|c|c|c|c|c|c|c|c|}
\hline & \multicolumn{11}{|c|}{ BS grades of group one } & \multicolumn{11}{|c|}{ BS grades of group two } \\
\hline & 1 & 2 & 3 & 4 & 5 & 6 & 7 & 8 & 9 & 10 & 11 & 12 & 13 & 14 & 15 & 16 & 17 & 18 & 19 & 20 & 21 & 22 \\
\hline 1 & - & 0.745 & 0.684 & 0.689 & 0.650 & 0.771 & 0.793 & 0.733 & 0.698 & 0.683 & 0.825 & 0.578 & 0.680 & 0.678 & 0.757 & 0.777 & 0.797 & 0.634 & 0.672 & 20.731 & 0.772 & 0.620 \\
\hline 2 & & - & 0.819 & 0.869 & 0.777 & 0.882 & 0.852 & 0.870 & 0.800 & 0.832 & 0.739 & 0.600 & 0.659 & 0.674 & 0.627 & 0.584 & 0.743 & 0.665 & 0.741 & 10.696 & 0.644 & 0.729 \\
\hline 3 & & & - & 0.848 & 0.729 & 0.763 & 0.783 & 0.869 & 0.783 & 0.744 & 0.742 & 0.643 & 0.671 & 0.589 & 0.589 & 0.700 & 0.599 & 0.721 & 0.801 & 10.675 & 0.545 & 0.776 \\
\hline 4 & & & & - & 0.815 & 0.820 & 0.860 & 0.875 & 0.478 & 0.860 & 0.718 & 0.686 & 0.703 & 0.658 & 0.687 & 0.622 & 0.688 & 0.740 & 0.697 & 70.687 & 0.672 & 0.739 \\
\hline 5 & & & & & - & 0.790 & 0.762 & 0.753 & 0.747 & 0.817 & 0.623 & 0.672 & 0.652 & 0.639 & 0.779 & 0.503 & 0.524 & 0.692 & 0.762 & 20.644 & 0.530 & 0.711 \\
\hline 6 & & & & & & - & 0.867 & 0.921 & 0.822 & 0.854 & 0.724 & 0.633 & 0.714 & 0.637 & 0.649 & 0.592 & 0.681 & 0.726 & 0.800 & 0.718 & 0.717 & 0.753 \\
\hline 7 & & & & & & & - & 0.822 & 0.768 & 0.827 & 0.830 & 0.753 & 0.800 & 0.777 & 0.822 & 0.712 & 0.726 & 0.711 & 0.772 & 20.774 & 0.718 & 0.732 \\
\hline 8 & & & & & & & & - & 0.823 & 0.834 & 0.664 & 0.711 & 0.704 & 0.694 & 0.742 & 0.728 & 0.670 & 0.691 & 0.718 & B 0.630 & 0.748 & 0.667 \\
\hline 9 & & & & & & & & & - & 0.860 & 0.570 & 0.701 & 0.595 & 0.627 & 0.693 & 0.622 & 0.701 & 0.598 & 0.705 & 50.607 & 0.644 & 0.681 \\
\hline 10 & & & & & & & & & & - & 0.758 & 0.712 & 0.669 & 0.702 & 0.783 & 0.706 & 0.556 & 0.722 & 0.792 & 20.674 & 0.594 & 0.821 \\
\hline 11 & & & & & & & & & & & - & 0.692 & 0.674 & 0.743 & 0.758 & 0.848 & 0.796 & 0.683 & 0.676 & 0.729 & 0.685 & 0.705 \\
\hline 12 & & & & & & & & & & & & - & 0.815 & 0.666 & 0.653 & 0.653 & 0.700 & 0.677 & 0.694 & 40.776 & 0.778 & 0.797 \\
\hline 13 & & & & & & & & & & & & & - & 0.849 & 0.769 & 0.797 & 0.767 & 0.820 & 0.718 & B 0.781 & 0.804 & 0.734 \\
\hline 14 & & & & & & & & & & & & & & - & 0.800 & 0.757 & 0.751 & 0.671 & 0.750 & 0.810 & 0.788 & 0.804 \\
\hline 15 & & & & & & & & & & & & & & & - & 0.656 & 0.644 & 0.665 & 0.713 & $\begin{array}{ll}30.695\end{array}$ & 0.656 & 0.762 \\
\hline 16 & & & & & & & & & & & & & & & & - & 0.865 & 0.785 & 0.691 & 10.807 & 0.882 & 0.738 \\
\hline 17 & & & & & & & & & & & & & & & & & - & 0.710 & 0.658 & B 0.859 & 0.853 & 0.661 \\
\hline 18 & & & & & & & & & & & & & & & & & & - & 0.813 & 30.765 & 0.824 & 0.767 \\
\hline 19 & & & & & & & & & & & & & & & & & & & - & 0.775 & 0.685 & 0.842 \\
\hline 20 & & & & & & & & & & & & & & & & & & & & - & 0.840 & 0.860 \\
\hline 21 & & & & & & & & & & & & & & & & & & & & & - & 0.738 \\
\hline 22 & & & & & & & & & & & & & & & & & & & & & & - \\
\hline
\end{tabular}

BS, bandsharing; SM, similarity matrix. 


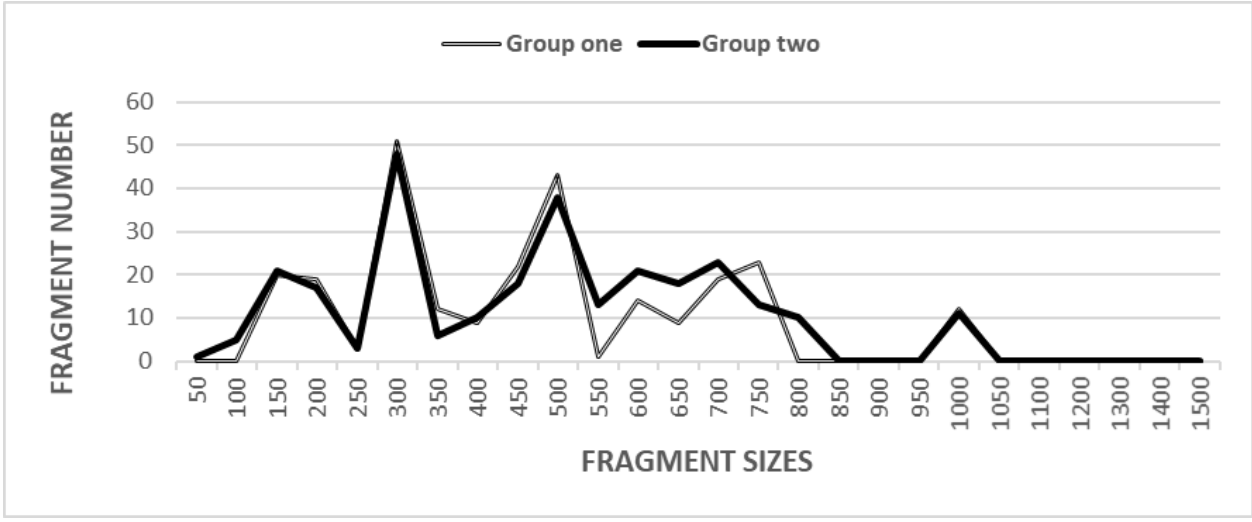

Fig. 1. Dissemination of FR amounts of two Scapharca subcrenata groups from Yeosu. Solid grey lines: Group one (SUBCRENATA 01, 09, 11, 12, 13, 14, 15, 16, 17, 18, 19, 20, 21, and 22). Solid black lines: Group two (SUBCRENATA 02, 03, 04, 05, 06, 07, 08, and 10). The FR numbers in each size interval have been computed from the combined FRs took with every five ON-polymers. The greater FR volumes $(>1,050 \mathrm{bp})$ are not noted in the Scapharca subcrenata bi-group. Remarkably, the banding shapes were altered greatly from 550 bp to 850 bp between two clam groups. FR, fragment; ON-polymer, oligonucleotides polymer.

OPD-15 made number of LUECP and number of LSTCP in two Scapharca subcrenata groups, as demonstrated in Table 2. The ON-polymer OPD-01 produced 33 loci LUECP, which were defining each population, almost $300 \mathrm{bp}, 450 \mathrm{bp}$, and $500 \mathrm{bp}$, in the group one. Also, the 33 LUECP in the shellfish specimen made by the OPD-09 were approximately $300 \mathrm{bp}, 500 \mathrm{bp}$, and 900 bp in size. Strangely, the ON-polymer OPD-15 recognized 22 LSTCP, dissimilar FRs of sizes $300 \mathrm{bp}$, which were corresponding in all specimens. The median number of LUECP was assorted and 1.2-fold greater in the shellfish group two than in the clam group one. As regards mean BS effects, entities in the clam group one $(0.779 \pm 0.011)$ had a little higher BS grades than did entities from the shellfish group two $(0.756 \pm 0.009)(p<0.05)$, as displayed in Table 3 .

In the present study, the entities of the shellfish group one are not tightly assembled with other entities of the invertebrate group two (Fig. 2). The PDG acquired by the five ON-polymers indicates two inherent groups: constellation I (SUBCRENATA 01, 09, 11, 12, 13, 14, 15, 16, 17, 18, 19, 20, 21, and 22) and constellation II (SUBCRENATA 02, 03, 04, 05, 06, 07, 08, and 10). Amid the twentytwo shellfish, the smallest GD that exhibited momentous molecular alterations was between entities

Table 2. The number of LUECP and LSTCP of two Scapharca subcrenata group made by PCR analysis using $5 \mathrm{ON}$-polymers

\begin{tabular}{ccccc}
\hline \hline Item & \multicolumn{2}{c}{ No. of LUECP } & & No. of LSTCP \\
\cline { 5 - 5 } ON-polymer & Group one & Group two & & $\begin{array}{c}\text { Two groups } \\
\text { (11 individuals per group) }\end{array}$ \\
\hline OPD - 01 & 33 & 44 & 66 \\
OPD - 02 & 33 & 33 & 22 \\
OPD - 08 & 11 & 11 & 22 \\
OPD - 09 & 22 & 33 & 44 \\
OPD - 15 & 11 & 11 & 22 \\
\hline Total no. & 110 & 132 & 176 \\
\hline Median no. per ON-polymer & 22.0 & 26.4 & 35.2
\end{tabular}

LUECP, loci unique to each clam population; LSTCP, loci shared by the two clam populations; ON-polymer, oligonucleotides polymer 
Table 3. Assorted calculations of numerical BS grades (mean \pm SE) amid binary Scapharca subcrenata groups were formed along the lines of the BS grades and SM

\begin{tabular}{lcc}
\hline \hline Group & Group one & Group two \\
\hline Group one & $0.779 \pm 0.011^{\mathrm{a}}$ & $0.687 \pm 0.006^{\mathrm{b}}$ \\
Group two & - & $0.756 \pm 0.009^{\mathrm{ab}}$ \\
\hline
\end{tabular}

Each rate is an outcome of tri-dissimilar trials.

${ }^{a-c}$ Rates with unlike superscript are significantly disparate, $p<0.05$.

BS, bandsharing; SE, standard error; SM, similarity matrix.

\section{Cluster Tree}

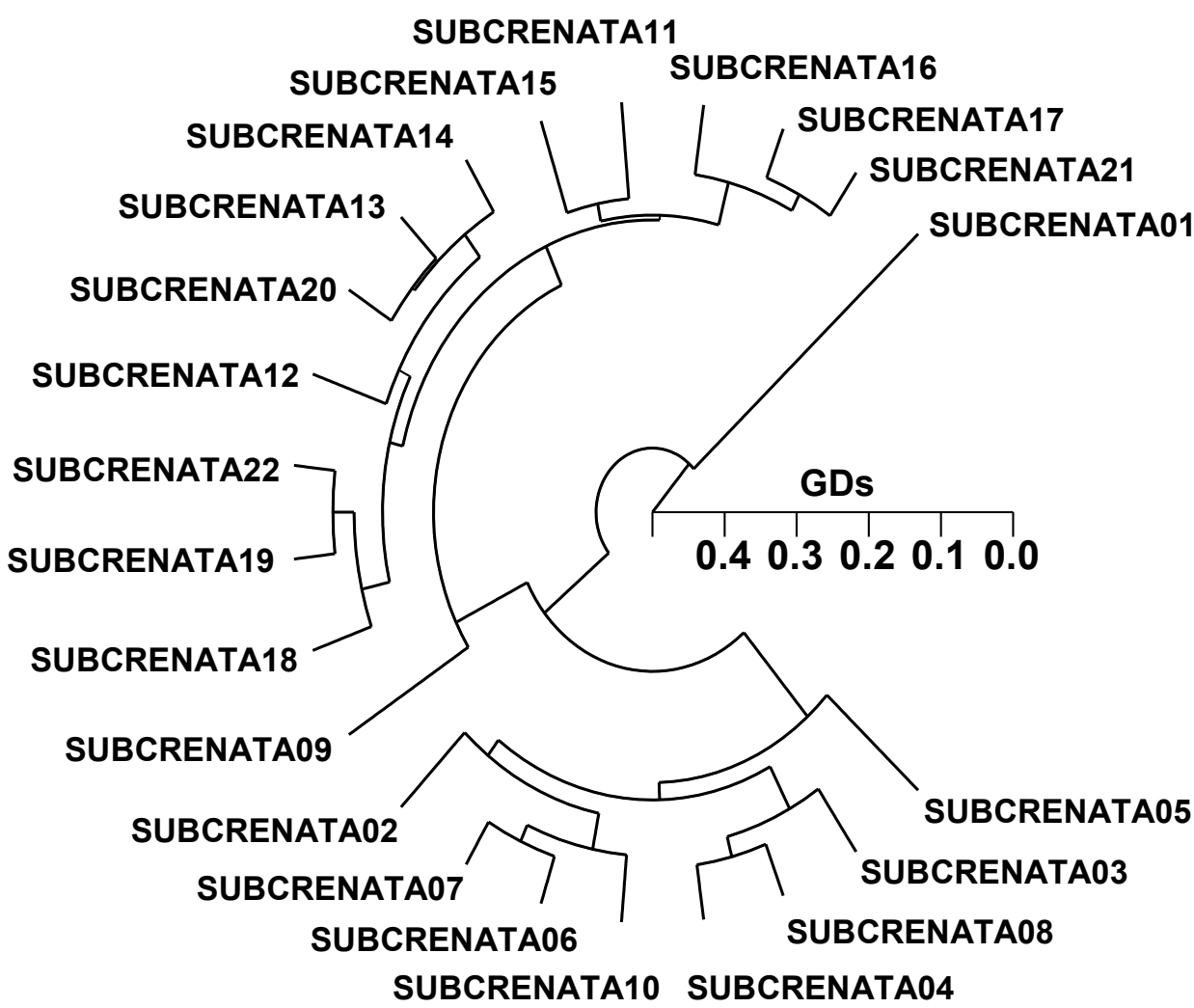

Fig. 2. Hierarchical PDG of GDs acquired from two invertebrate (Scapharca subcrenata) groups. The association between different entities of two shellfish groups from group I (SUBCRENATA 01, 09, 11, $12,13,14,15,16,17,18,19,20,21$, and 22) and group II (SUBCRENATA 02, 03, 04, 05, 06, 07, 08 , and 10) made in line with the BS grades and SM. PDG, polar dendrogram; GD, genetic distance; BS, bandsharing; SM, similarity matrix.

shellfish no. 22 and no. 19 from the constellation II (GD=0.057), while the largest GD among the 22 entities that exposed substantial molecular alterations was between entities clam no. 02 and clam no. 01 (GD=0.422). So, the GD (0.422) of this shellfish (SUBCRENATA 02 and 01) is 7.41-fold innately distinct to the GD (0.057) of the other shellfish (SUBCRENATA 22 and 19).

Above-mentioned, a PDG revealed close or distant relationships between entity structures amid bare figures and farmed varieties of discus (Symphysodon spp.) (Koh et al., 1999). Yoon (2018) reported that cluster analysis, which indicated two inherent constellations, revealed a relationship between the entities within two shellfish groups comparatively speaking other invertebrates. In the 
other shellfishes, cluster enquiry of the pairwise group matrix, created from heritable documents, indicated that geographically close groups be disposed to accumulate collectively in the blacklip abalone (Huang et al., 2000). S. subcrenata bi-group can be obviously categorized by gDNAgrounded processes.

The aptitude of ON-polymers augmented DNAs to determine unique markers for line, strain, species, genus, and group proof of identity in life entities (Koh et al., 1999; Esselman et al., 2000; Huang et al., 2000; Kim et al., 2000; Dixon et al., 2004; García et al., 2004; Araneda et al., 2005; Yamazaki et al., 2005; Yan et al., 2005; Gelin \& Souty-Grosset, 2006; Godhe et al., 2006; Kim et al., 2006; Yoon \& Kim, 2010; Kang \& Yoon, 2013; Oh \& Yoon, 2014; Kim \& Yoon, 2018) has also been well approved. Great point of an important GD between two Scapharca subcrenata groups showed this research process is one of the most appropriate apparatuses for biotechnological DNA studies on entities and units of other life beings (Koh et al., 1999; Zhou et al., 2000; Kim \& Choi, 2003; Dixon et al., 2004; Liu et al., 2004; Araneda et al., 2005; Godhe et al., 2006; Yoon, 2019; Yoon \& Kim, 2010; Kang \& Yoon, 2013; Yoon, 2020).

\section{REFERENCES}

Araneda C, Neira R, Iturra P (2005) Identification of a dominant SCAR marker associated with colour traits in coho salmon (Oncorbynchus kisutch). Aquaculture 247:67-73.

Dixon BA, Shinn AP, Sommerville C (2004) Genetic characterization of populations of the ectoparasitic caligid, Lepeophtheirus salmonis (Krøyer 1837) using randomly amplified polymorphic DNA. Aquac Res 35:730-741.

Esselman EJ, Crawford DJ, Brauner S, Stuessy TF, Anderson GJ, Silva OM (2000) RAPD marker diversity within and divergence among species of Dendroseris (Asteraceae:Lactuceae). Am J Bot 87:591-596.

García G, Claramunt S, Lalanne AI (2004) Genetic differentiation among annual fishes of the genus Cynolebias (Cyprinodontiformes, Rivuluidae) in a biosphere reserve site from Uruguay. Environ Biol Fishes 70:247-256.

Gelin A, Souty-Grosset C (2006) Species identification and ecological study of the genus Palaemonetes (Decapoda:Caridea) in the French Mediterranean. J Crust Biol 26:124-133.

Godhe A, McQuoid MR, Karunasagar I, Karunasagar I, Rehnstam-Holm AS (2006) Comparison of three common molecular tools for distinguishing among geographically separated clones of the diatom Skeletonema marinoi Sarno et Zingone (Bacillariophyceae).J Phycol 42:280-291.

Huang BX, Peakall R, Hanna PJ (2000) Analysis of genetic structure of blacklip abalone (Haliotis rubra) populations using RAPD, minisatellite and microsatellite markers. Mar Biol 136:207216.

Kang SK, Yoon JM (2013) Geographic variations of three Fulvia mutica populations. Korean J Malacol 29:163-169.

Kim HJ, Kang JS, Jung SW, Park YJ (2019) Changes in planktonic bivalve larvae of Tegillarca granosa and Anadara kagoshimensis in the Boseong coastal waters of South Korea. Korean J Environ Biol 37:351-361.

Kim SK, Jung YH, Han SH, Oh YS, Ko MH, Oh MY (2000) Phylogenetic relationship among Haliotis spp. distributed in Korea by the RAPD analysis. Korean J Genet 22:43-49.

Kim CK, Choi HK (2003) Genetic diversity and relationship in Korean ginseng (Panax scbinseng) based on RAPD analysis. Korean J Genet 25:181-188.

Kim S, Kim YH, Yoon JM (2006) Genetic variation in geographic crayfish (Cambaroides similis) 
populations.J Fish Pathol 19:141-153.

Kim SY, Shin YK, Lim HK, Lee WC (2008) Gonadal development and reproductive cycle of the ark shell Scapharca subcrenata (Bivalvia:Arcidae) from Yeoja bay.J Aquac 21:252-258.

Kim YS, Yoon JM (2018) Genetic distances in two Gracilaria species (Gracilariaceae, Rhodophyta) identified by PCR technique. Dev Reprod 22:393-402.

Koh TL, Khoo G, Fan LQ, Phang VPE (1999) Genetic diversity among wild forms and cultivated varieties of discus (Symphysodon spp.) as revealed by random amplified polymorphic DNA (RAPD) fingerprinting. Aquaculture 173:485-497.

Lee JH (1998) A study on sexual maturation of the ark shell, Scapharca subcrenata Lischke. Korean J Malacol 14:91-102.

Liu Y, Wang X, Liu L (2004) Analysis of genetic variation in surviving apple shoots following cryopreservation by vitrification. Plant Sci 166:677-685.

Oh H, Yoon JM (2014) Genetic distances of three mollusk species investigated by PCR analysis. Dev Reprod 18:43-49.

Shin SB, Oh EG, Jeong SH, Lee HJ, Kim YK, Lee TS (2016) Assessment of bacteriological safety of the seawater and ark shell (Scapharca subcrenata) in Yeoja bay, Korea.J Fish Mar Sci E 28:1435-1443.

Yamazaki Y, Shimada N, Tago Y (2005) Detection of hybrids between masu salmon Oncorbynchus masou masou and amago salmon O. m. ishikawae occurred in the Jinzu river using a random amplified polymorphic DNA technique. Fish Sci 71:320-326.

Yan J, Liu S, Sun Y, Zhang C, Luo K, Liu Y (2005) RAPD and microsatellite analysis of diploid gynogens from allotetraploid hybrids of red crucian carp (Carassius auratus) $\times$ common carp (Cyprinus carpio). Aquaculture 243:49-60.

Yoon JM, Kim JY (2004) Genetic differences within and between populations of Korean catfish (S. asotus) and bullhead (P. fulvidraco) analysed by RAPD-PCR. Asian-Australas J Anim Sci 17:1053-1061.

Yoke-Kqueen C, Radu S (2006) Random amplified polymorphic DNA analysis of genetically modified organisms.J Biotechnol 127:161-166.

Yoon JM, Kim JY (2010) Genetic differences and geographic variation in cuttle fish (Sepia esculenta Hoyle). Dev Reprod 14:163-170.

Yoon JM (2018) Genetic variations of intra- and between-razor clam Solen corneus population identified by PCR analysis. Dev Reprod 22:193-198.

Yoon JM (2019) Genetic distances within-population and between-population of tonguesole, Cynoglossus spp. identified by PCR technique. Dev Reprod 23:297-304.

Yoon JM (2020) Genetic differences in natural and cultured river pufferfish populations by PCR analysis. Dev Reprod 24:327-335.

Zhou L, Wang Y, Gui JF (2000) Analysis of genetic heterogeneity among five gynogenetic clones of silver crucian carp, Carassius auratus gibelio Bloch, based on detection of RAPD molecular markers. Cytogenet Cell Genet 88:133-139. 
